\title{
CARACTERIZACIÓN DE DAÑOS PRODUCIDOS POR Meloidogyne spp. (NEMATA: TYLENCHIDA) EN LA VID EN MENDOZA, ARGENTINA
}

\section{CHARACTERIZATION OF DAMAGE CAUSED BY Meloidogyne spp. (NEMATA:TYLENCHIDA) IN GRAPEVINES IN MENDOZA, ARGENTINA}

\author{
Carla Vanina Dagatti B. ${ }^{1}$; Violeta Cristina Becerra²; María Eugenia Herrera³
}

Fecha de recepción: Julio 11 de 2014

Fecha de aceptación: Septiembre 22 de 2014

\section{RESUMEN}

El objetivo de esta investigación fue comparar y establecer relaciones entre los diferentes indicadores de crecimiento entre plantas de vid con dos niveles de infestación (alto y leve) de Meloidogyne spp. El estudio se realizó en un viñedo cv Merlot, situado en Agrelo, Mendoza, donde se escogieron 2 parcelas, con y sin nematodos, con diferentes niveles de crecimiento vegetativo. Los indicadores a evaluar fueron: peso y número de racimos por planta, peso de poda, cantidad de entrenudos y área foliar de hojas y feminelas. El grado de infestación de nematodos de cada parcela se determinó mediante la técnica flotación - centrifugación. Para el análisis estadístico se utilizó la prueba de wilcoxon (Mann Whitney U) y el test de student. Además, mediante un análisis de regresión lineal, se comprobó si existía relación entre los indicadores evaluados y la densidad de población de Meloidogyne spp. expresado en número de estados juveniles (J2) presentes en el suelo. Los resultados indicaron que la parcela con menor densidad poblacional de juveniles de Meloidogyne spp., presentó mayor peso promedio de madera de poda, así como también un área foliar de hojas y feminelas superior. Con respecto al peso promedio de racimos por planta, dicha parcela también superó a aquella con alta concentración de nematodos.

Palabras clave: viñedos, protección vegetal, nematodos, Vitis vinifera.

1 Investigador en Estación Experimental Agropecuaria Mendoza INTA. Licenciada en Biología. Mendoza. Argentina. dagatti.carla@ inta.gob.ar

2 Investigador en Estación Experimental Agropecuaria Mendoza INTA. M. Sc. Ingeniera Agrónoma. Mendoza. Argentina. becerra. violeta@inta.gob.ar

3 Investigador en Estación Experimental Agropecuaria Mendoza INTA. Ingeniera Agrónoma. Mendoza. Argentina. herrera.mariae@ inta.gob.ar 


\begin{abstract}
The aim of this research was to compare and establish relationships between different growth indicators of grapevines with two levels of infestation (high and low) of Meloidogyne spp. The study was conducted in a vineyard cv Merlot, located in Agrelo, Mendoza, where two plots (A and B), with and without nematodes, and with different levels of vegetative growth were chosen. The evaluated indicators were: weight and number of bunch stems per plant, pruning weight, number of internodes, and leaf and feminelle area. The degree of nematode infestation per plot was determined by the flotation - centrifugation technique. Statistical analyses were performed through the Wilcoxon (Mann Whitney U) test and Student Test. Furthermore, a linear regression analysis was used to verify the existence of a relationship between the assessed indicators and the population density of Meloidogyne spp., expressed as the number of juvenile states (J2) in the soil. The results indicate that plot with the lower population density of juveniles of Meloidogyne spp., showed a greater average weight of pruning wood, as well as superior leaf and feminelle area. Regarding the average weight of bunch stems per plant, this plot also out performed the plot with a high concentration of nematodes.
\end{abstract}

Keywords: Vineyard, plant protection, nematodes, Vitis vinifera.

\section{INTRODUCCIÓN}

Argentina ocupa un importante lugar en el contexto vitivinícola internacional y comienza a posicionarse como un exportador altamente competitivo de los tradicionales países productores de vid tales como Francia, España e Italia. La superficie actual cultivada es de 221.202 ha que representa el 2,81\% de la superficie mundial. En Mendoza, la vid es el cultivo más importante, con el 71,06\% de la superficie del país (INV, 2012).

El viñedo es afectado por diversos patógenos y entre éstos, los nematodos juegan un papel importante. Los nematodos comprenden un gran Phyllum dentro del reino animal que incluye parásitos de plantas y animales, así como también especies de vida libre (Maggenti, 1981). Comprenden distintas especies presentes en una amplia variedad de suelos, desde los cultivados hasta aquellos que no lo son (Doucet, 1991). Los nematodos fitoparásitos pueden causar serios daños a numerosos cultivos, disminuyendo su producción anual (Williamsom y Hussey, 1996) y acortando la vida de las plantas (Cucchi y Becerra, 2009). Particularmente la vid es hospedero de muchas especies de nematodos que son capaces de ocasionar alteraciones, por su acción directa en el desarrollo de sus actividades tróficas (Doucet, 1980) e indirecta por ser vectores de agentes patógenos incluidos los virus (Brown et al., 1995).

Meloidogyne spp. es uno de los géneros de nematodos más importantes debido a las pérdidas que produce en los cultivos, ya que induce alteraciones en las raíces provocando agallas (Doucet, 1993). Para esto, rompe las células de la planta, disuelve las paredes celulares o induce cambios fisiológicos en los tejidos radicales como resultado de la inyección de sustancias fitotóxicas a través de su estilete (Melakeberhan y Ferris, 1989). Estas afecciones provocan una predisposición de la planta al ataque de otros 
microorganismos patógenos como hongos, bacterias y virus que penetran la planta a través de las heridas ocasionadas por el nematodo (Brown et al., 1995). Se trata de especies endoparásitas obligadas, capaces de adaptarse a una gran cantidad de plantas huéspedes y con una elevada tasa de reproducción con varias generaciones por año (Siddiqi, 2000). Son responsables de considerables reducciones de los rendimientos así como de la calidad del producto y si las densidades de población en el suelo son muy elevadas pueden observarse zonas donde las plantas presentan un crecimiento muy reducido, con hojas cloróticas y marchitas (Magunacelaya y Dagnino, 1999). A nivel mundial, entre los $35^{\circ}$ de latitud sur y $35^{\circ}$ de latitud norte, el género Meloidogyne se encuentra ampliamente distribuido, ya que sus especies se encuentran adaptadas a climas cálidos (Taylor y Sasser, 1983). En Argentina han sido identificadas 10 especies (Doucet y Lax, 2007) entre las cuales Meloidogyne javanica, Meloidogyne hapla, Meloidogyne arenaria y Meloidogyne incognita son consideradas las más importantes (Nicol et al., 1999). El daño que estos nematodos provocan, suele ser de muy difícil evaluación debido, por un lado, a su asociación con otros organismos patógenos y, por otro, al hecho de que los síntomas que provocan son generalmente inespecíficos: falta de vigor, bajo rendimiento, decoloraciones y poca resistencia a la sequía que pueden confundirse con estrés hídrico o deficiencias nutricionales (Cucchi y Becerra, 2009).

Los viñedos son altamente sensibles al daño de Meloidogyne spp. el cual suele ser más severo en suelos arenosos (Magunacelaya y Dagnino, 1999). Según el hábito de vida, los síntomas pueden aparecer en la parte aérea de la planta como falta de crecimiento, clorosis, marchitamiento, defoliación o en las raíces que puede traducirse en reducción del sistema radical, necrosis, escasez de raicillas, nódulos o agallas y quistes.

Los síntomas difieren entre cultivares, aunque las plantas infestadas invariablemente presentan agallas en las raíces. Producen decrecimiento en las tasas de respiración y fotosíntesis (Magunacelaya y Dagnino, 1999). Según Di Vito et al. (2009), la reducción del crecimiento de las plantas de vid comenzaría a densidades de población del suelo tan bajas como 0,6 huevo $/ \mathrm{cm}^{3}$ de suelo.

La especie de nematodos fitoparásitos más importante que afecta a la vid es Meloidogyne spp (Carneiro et al., 2007). Es especialmente dañino en los cultivares de uva de vinificación tales como Cabernet Sauvignon, Chardonnay, Merlot y Syrah (Aballay et al., 2009).

De acuerdo con Ferris y Mckenry (1975) y Pinkerton et al. (1999), en muchos casos la relación entre la densidad poblacional de nematodos y la sanidad de las plantas es oscura y podría depender de los años del viñedo, del cultivar y la presencia de otros factores como el estrés hídrico, suelos pobres, estrés por enfermedades $\mathrm{u}$ otras plagas.

Las consideraciones anteriores y la poca información local disponible sobre este tema motivaron la realización del presente trabajo de investigación cuyos objetivos fueron: Comparar diferentes indicadores de crecimiento entre plantas con dos niveles de infestación (alto y leve) de Meloidogyne spp y establecer relaciones entre el número de nematodos del género Meloidogyne y los indicadores vegetativos a evaluar. 


\section{MATERIALES Y MÉTODOS}

El ensayo se realizó durante la temporada 2010 - 2011, en un viñedo de 52 hectáreas ubicado en la Ruta Nacional No 7, en la localidad de Agrelo, Luján de Cuyo. Dicha finca se encuentra a 994 msnm entre los paralelos $33^{\circ} 05^{\prime} 42,63^{\prime \prime}$ de latitud sur y $068^{\circ} 55^{\prime} 08,83^{\prime \prime}$ longitud oeste, infestado con nematodos del género Meloidogyne.

El sitio de estudio correspondió a dos parcelas de vid pie franco de cv. Merlot, de 10 años de implantación, infestadas con nematodos (en adelante parcelas A y B). Estas parcelas comprenden un área de 4,3 hectáreas, están establecidas con una distancia de plantación de 1,5 m sobre la hilera y $2 \mathrm{~m}$ entre hileras, son conducidas en espaldero y regadas por goteo. Todas las plantas tuvieron condiciones de manejo semejantes. El tipo de poda utilizado es cordón bilateral. El suelo es de textura franca, con $\mathrm{pH}$ neutro-alcalino $(\mathrm{pH}=7,64)$, con un bajo contenido de materia orgánica $(1,39 \%)$, baja disponibilidad de Nitrógeno $\left(738 \mathrm{mg} \cdot \mathrm{Kg}^{-1}\right)$ y alta de Fósforo (9,8 mg. $\mathrm{Kg}^{-1}$ ) y Potasio (209 mg. $\left.\mathrm{Kg}^{-1}\right)$. Las parcelas se encuentran una a continuación de la otra por lo que se asume que no hay diferencias en cuanto a la composición del suelo. Para establecer el ensayo se escogieron al azar 10 plantas de cada parcela, cada una de las cuales representó una repetición.

Para llevar a cabo los objetivos, de cada parcela se evaluaron las siguientes variables: peso de la madera de poda $\left(\mathrm{Kg}\right.$. planta $\left.^{-1}\right)$, crecimiento de los brotes $(\mathrm{cm})$, largo de los entrenudos $(\mathrm{cm})$, área foliar de hojas y feminelas $\left(\mathrm{mm}^{2}\right)$, peso $(\mathrm{Kg}$. planta $\left.^{-1}\right)$ y cantidad de racimos $\left(n^{\circ} \cdot\right.$ planta $\left.^{-1}\right)$ y tenor azucarino $\left({ }^{\circ}\right.$ Brix.parcela $\left.{ }^{-1}\right)$.

Este estudio estuvo comprendido por dos fases: una de campo y otra de laboratorio.

\section{Fase de campo}

Determinación de la densidad de población de Meloidogyne spp

Con la finalidad de conocer el nivel de población inicial de nematodos, se analizaron muestras de suelo de ambas parcelas tanto en verano como en invierno, épocas de mayor densidad de nematodos. Las muestras se extrajeron con pala de punta eliminando los primeros 5 $\mathrm{cm}$ de suelo. Se sacó una palada de $30 \mathrm{~cm}$ de profundidad que se desechó y a continuación se extrajo una segunda palada abarcando todo el perfil de una de las caras del pozo y el fondo. Las muestras de aproximadamente $1 \mathrm{Kg}$ de suelo fueron colocadas en bolsas de polietileno, cerradas y etiquetadas. Este procedimiento se efectuó para cada una de las repeticiones de ambas parcelas.

\section{Peso de poda}

En cada una de las repeticiones de las parcelas en estudio, en invierno se realizó la poda de tipo cordón bilateral. El material vegetal obtenido se pesó en balanza granataria.

\section{Medición de brotes y conteo de entrenudos}

De cada planta marcada se extrajeron 2 brotes, uno del extremo de un brazo y otro del lugar de nacimiento del mismo. Éstos identificados, medidos con cinta métrica y contados sus entrenudos.

\section{Determinación de cantidad y peso de racimos}

En la época de cosecha, se extrajeron todos los racimos de las 10 plantas marcadas de cada parcela. Los frutos se colocaron en bolsas de polietileno cerradas y etiquetadas. 


\section{Determinación de la concentración de sólidos solubles}

Se extrajeron 200 bayas al azar de las 10 repeticiones de cada parcela, de diferentes partes del racimo.

\section{Fase de laboratorio}

Determinación de la densidad de población de Meloidogyne spp.

De cada parcela se tomaron 10 muestras de suelo las cuales se procesaron por separado. La extracción de estados juveniles infestivos (J2) se realizó con la técnica de Jenkins (1964), la cual, consta de dos partes: flotación - tamizado y centrifugación. En la primera etapa, se realizó la sedimentación de la muestra de suelo en suspensión acuosa, quedando suspendidos los nematodos junto con arcillas y materia orgánica. La segunda etapa estuvo constituida por dos centrifugaciones sucesivas; la primera permitió separar los nematodos y arcillas de la materia orgánica y la segunda separar los nematodos de la fase mineral, para lo que se utilizó una solución azucarada estándar de densidad de 1.15 - 1.18 g.ml ${ }^{-1}$, condición necesaria para que los organismos se mantengan en suspensión. Una vez obtenido el extracto se procedió al recuento de los nematodos presentes $\left(\mathrm{N}^{0}\right.$ de estados juveniles de Meloidogyne spp. en 500g de suelo).

\section{Peso de poda}

Los sarmientos obtenidos en campo fueron llevados al laboratorio donde se pesaron con balanza granataria.

\section{Determinación de área foliar}

De cada uno de los brotes medidos en campo, se extrajeron todas las hojas y feminelas y posteriormente se estableció el área foliar en $\mathrm{mm}^{2}$ con un scanner y el software LeafAreaMeasurement v 3.1 (@2003 TheUniversity of Sheffield. A.P. Askew).

\section{Determinación de cantidad y peso de racimos} Los racimos provenientes del campo se llevaron al laboratorio donde se realizó el conteo y posterior pesado de los mismos con balanza granataria.

\section{Determinación de la concentración de sólidos solubles}

Las bayas extraídas se colocaron en un recipiente plástico donde se realizó su molienda y con el mosto obtenido se determinaron los sólidos solubles por refractometría. Se realizaron tres lecturas para disminuir el error.

Los datos obtenidos fueron sometidos a una prueba de test de student para los datos normales y con el test de Wilcoxon (Mann Whitney U) se analizaron los datos que no se ajustaron a una distribución normal. Por otra parte, se realizó un análisis de regresión lineal para comprobar si existía relación entre los diferentes indicadores evaluados y la densidad de población de Meloidogyne spp. expresado en número de juveniles presentes en el suelo.

\section{RESULTADOS}

La densidad de población de Meloidogyne spp. en cada parcela estudiada, se muestra en la Figura 1. 


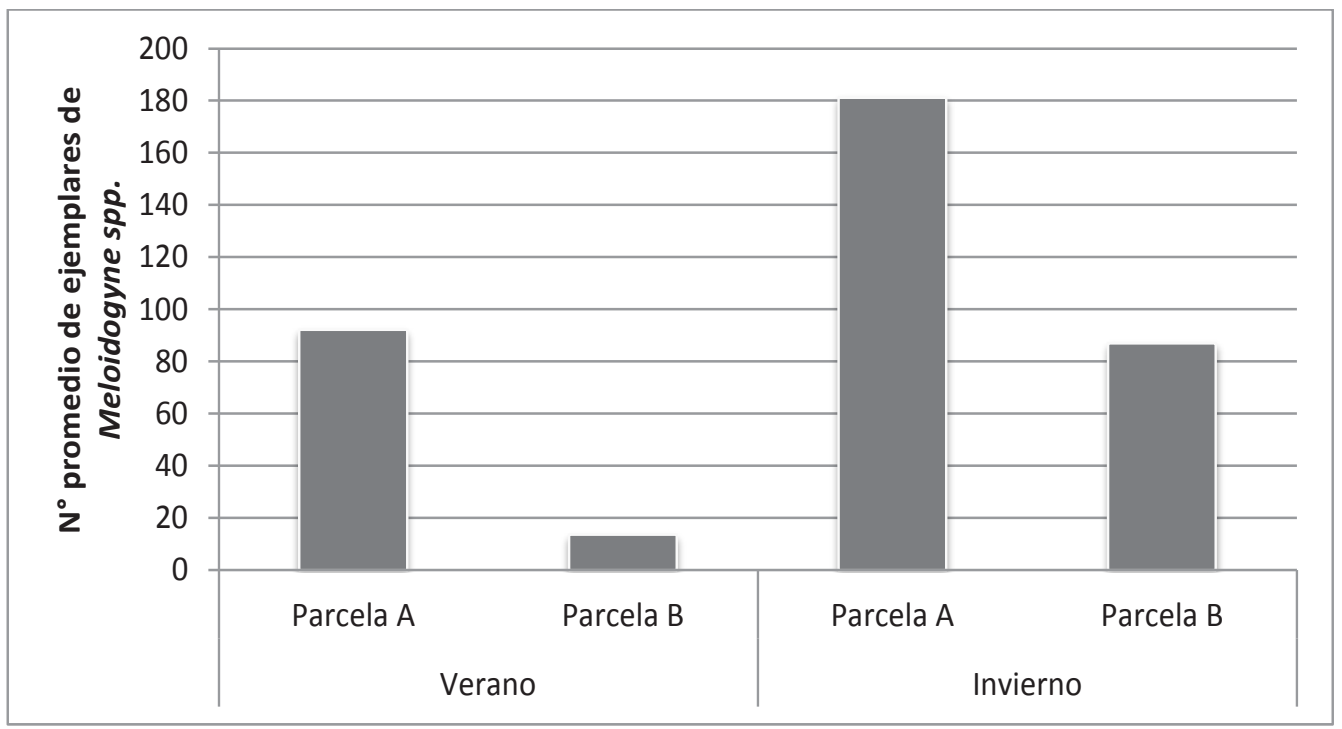

Figura $1 . N^{\circ}$ promedio de juveniles de Meloidogyne spp. en 500g de suelo en época estival e invernal en una parcela de vid con alta infestación (Parcela A) y otra parcela con baja infestación (Parcela B). Temporada 2010 - 2011. Agrelo, Mendoza.

En la tabla 1 se muestra los resultados de las Pruebas de Wilcoxon (Mann Whitney U) y test de student para las variables estudiadas.

Tabla 1. Evaluación de variables de crecimiento en la vid, en parcelas con alta infestación de Meloidogyne spp (Parcela A) y baja infestación del nematodo (Parcela B), NS: no difiere significativamente, Me: mediana, x: media, sd: desviación estándar

\begin{tabular}{l|r|r|r|r|r|r}
\hline \multicolumn{1}{c|}{ Variables } & \multicolumn{1}{c|}{$\begin{array}{c}\text { Parcela A } \\
\mathrm{x} \pm \mathrm{sd}\end{array}$} & $\begin{array}{c}\text { Parcela B } \\
\mathrm{x} \pm \mathrm{sd}\end{array}$ & $\begin{array}{c}\text { Parcela A } \\
\text { Me }\end{array}$ & $\begin{array}{c}\text { Parcela B } \\
\mathrm{Me}\end{array}$ & Estadígrafo & p-valor* \\
\hline $\begin{array}{l}\mathrm{N}^{\mathrm{o}} \text { de J2 en 500g de } \\
\text { suelo }\end{array}$ & $72,70 \pm 42,45$ & $4,60 \pm 3,41$ & 63,50 & 4 & $\mathrm{~W}=155$ & 0,0002 \\
\hline Peso de poda (g) & $215,63 \pm 70,67$ & $359,14 \pm 107,46$ & 239,68 & 374,81 & $\mathrm{~T}=2,62$ & 0,0175 \\
\hline $\mathrm{N}^{\mathrm{o}}$ de entrenudos & $12 \pm 4,09$ & $8,10 \pm 3,35$ & 11 & 7,5 & $\mathrm{~T}=-1,72$ & $0,9234 \mathrm{NS}$ \\
\hline Área foliar $\left(\mathrm{cm}^{2}\right)$ & $1613,21 \pm 603,42$ & $2421,82 \pm 774,19$ & 1747,99 & 2366,05 & $\mathrm{~T}=2,61$ & 0,0179 \\
\hline $\mathrm{N}^{\text {o de racimos }}$ & $15,2 \pm 9,51$ & $24,8 \pm 7,81$ & 13,50 & 24 & $\mathrm{~T}=2,05$ & $0,0556 \mathrm{NS}$ \\
\hline Peso de racimos (Kg) & $0,34 \pm 0,06$ & $2,157 \pm 0,53$ & 0,34 & 2,12 & $\mathrm{~W}=45$ & $<0,0001$ \\
\hline $\begin{array}{l}\text { Concentración de } \\
\left.\text { sólidos solubles ( }{ }^{\circ} \text { Brix }\right)\end{array}$ & $23 \pm 1$ & $25,83 \pm 1,26$ & 23 & 26 & $\mathrm{~T}=6$ & $0,1 \mathrm{NS}$ \\
\hline
\end{tabular}

${ }^{*} \mathrm{a}=0.05$

Con los resultados obtenidos en ambas parcelas, se realizó un análisis de regresión para comprobar si existe relación entre los indicadores evaluados en este estudio y la densidad poblacional de Meloidogyne spp. 


\section{Peso de poda}

En la relación entre el peso de poda y la densidad poblacional de juveniles del género Meloidogyne en ambas parcelas el coeficiente de regresión $\mathrm{R}^{2}$

fue de 0,8142 (Fig. 2). Esto significa que el 81,42\% de la variación del peso de poda en dicha parcela puede ser explicado por el número de juveniles presentes.



Figura 2. Dispersión de la relación entre el peso de poda en un viñedo y el número de juveniles (J2) de Meloidogyne spp. presentes.

Temporada 2010-2011. Agrelo, Mendoza

\section{Medición de entrenudos}

El coeficiente de regresión $\mathrm{R}^{2}$ obtenido en el cálculo de la regresión lineal entre la cantidad de entrenudos por brote y el número de juveniles de Meloidogyne spp. en las parcelas estudiadas fue de 0,5329 . Es decir que el $53,29 \%$ de la variación del número de entrenudos por brote, se debe a la densidad poblacional de juveniles de este nematodo (Fig. 3).



Figura 3. Dispersión de la relación entre la cantidad promedio de entrenudos por brote en un viñedo y el número de juveniles (J2) de Meloidogyne spp. Temporada 2010-2011. Agrelo, Mendoza 


\section{Determinación de área foliar}

El resultado obtenido del cálculo de la regresión lineal mostró que la relación entre el área foliar de hojas y feminelas y la densidad poblacional de juveniles del género Meloidogyne en ambas parcelas (Fig. 4) es media, ya que el coeficiente de regresión $\mathrm{R}^{2}$ fue de 0,6691. Esto significa que solo el $66,91 \%$ de la variación área foliar en dichas parcelas depende del número de juveniles presentes.

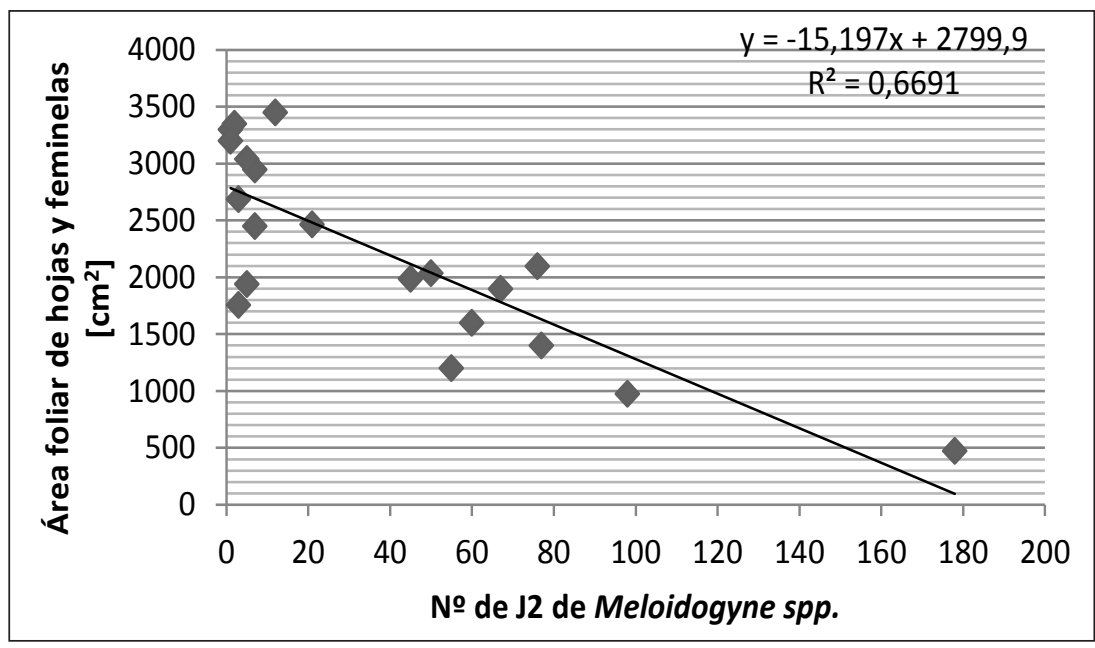

Figura 4. Dispersión de la relación entre el área foliar de hojas y feminelas de un viñedo y el número de juveniles (J2) de Meloidogyne spp. Temporada 2010-2011. Agrelo, Mendoza

\section{Cantidad de racimos}

El coeficiente de regresión $\mathrm{R}^{2}$ obtenido al relacionar el número promedio de racimos por planta y el número de juveniles de Meloidogyne spp. en ambas parcelas fue de 0,7562. Es decir que el $75,62 \%$ de la variación del promedio de racimos en las parcelas citadas, se debe a la densidad poblacional de juveniles de Meloidogyne spp. (Fig. 5).

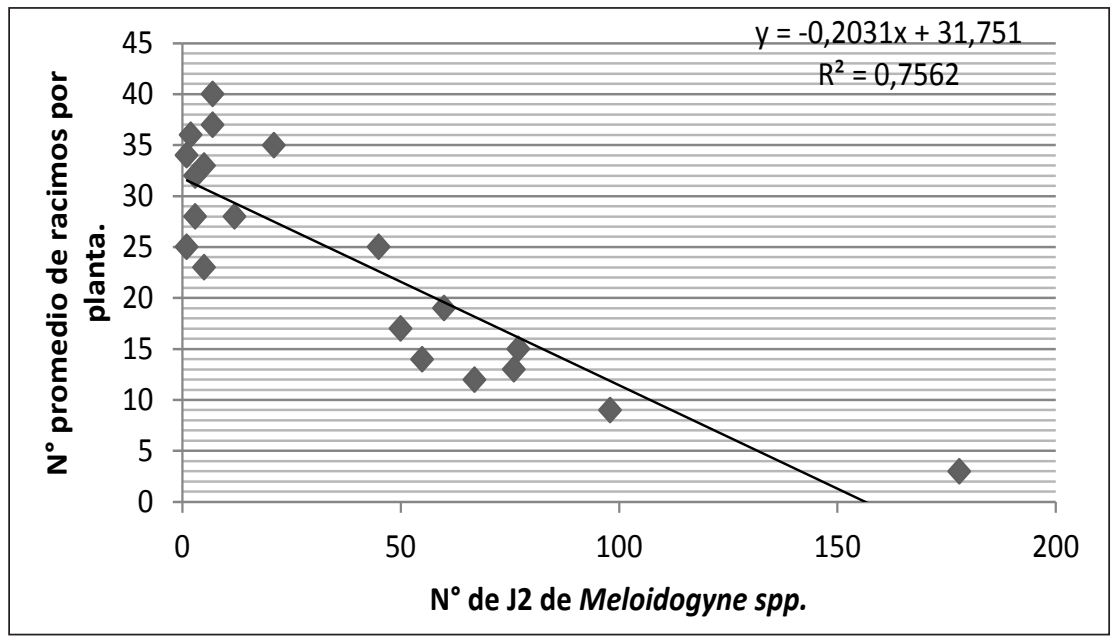

Figura 5. Dispersión de la relación entre el número promedio de racimos de uvas y el número de juveniles (J2) de Meloidogyne spp presentes en un viñedo. Temporada 2010-2011. Agrelo, Mendoza 


\section{Peso de racimos}

En la figura 6 se representa el diagrama obtenido de la relación existente entre el peso de racimos y el número de J2 de Meloidogyne spp. en las parcelas estudiadas. El coeficiente de regresión resultante fue de 0,8142 o sea que el $81,42 \%$ de la variación en el peso de racimos en las parcelas estudiadas se debe a la densidad de nematodos del género Meloidogyne.



Figura 6. Dispersión de la relación entre el peso de racimos de uvas y el número de juveniles (J2) de Meloidogyne spp. presentes en un viñedo.

Temporada 2010-2011. Agrelo, Mendoza

\section{DISCUSION}

Trabajos similares al presente se han realizado en condiciones controladas delaboratorio, en plantas en maceta infestadas con poblaciones conocidas de nematodos y luego se ha determinado el grado de agallamiento del sistema radical.

Los síntomas típicos que produceMeloidogyne, son las agallas en las raíces de las plantas infectadas, por lo que la absorción de agua y nutrientes se ve afectada. Como consecuencia de esto, el crecimiento de la planta se retarda, las hojas presentan deficiencia de nutrientes, marchitez, amarillamiento y necrosis, la floración se puede reducir y consecuentemente el número de frutos es menor. La aparición de estos síntomas es más rápida en verano que en otras estaciones dado que los requerimientos de nutrición y agua son mayores (Ornat y Sorribas, 2008).
Esta sintomatología se observa en varios cultivos tales como papa (Doucet y Lax, 2007), vid (Melakeberhan y Ferris, 1989; Nicol et al., 1999; Magunacelaya y Dagnino, 1999; Aballay et a.l, 2009; Rodriguez et al., 2011), tabaco (Salmerón y Cabello, 1989), cultivos hortícolas (Vega y Galmarini, 1970), entre otros. Al respecto, Olthof y Potter (1977) infestaron plantas de tomate con Meloidogyne hapla y concluyeron que a densidades por encima de las 2000 larvas por $\mathrm{Kg}$ de suelo, el rendimiento de la fruta era deprimido y la tasa de reproducción de los nematodos superó la tasa de expansión de las raíces de tomate. Por otra parte, Melakeberhan y Ferris (1989), infestaron plantas de Vitis vinifera con 1000, 2000, 4000 y 8000 J2 de $M$. incognita y midieron parámetros como área foliar, peso de poda, tasa de fotosíntesis, entre otros. Como resultado obtuvieron que el área foliar total de las plantas disminuyó en un $15 \%$ a medida que la población de nematodos 
se incrementaba, aunque este efecto no se observó en las hojas primarias. Con respecto a la producción, ésta no disminuyó al incrementarse la población de nematodos. Estos resultados no coinciden con lo observado en nuestro trabajo, donde el coeficiente de regresión $\mathrm{R}^{2}$ obtenido de la relación número y peso de racimos por planta con el número de J2 de Meloidogyne spp. fue de 0,7562 (Fig. 5) y de 0,8142 (Fig. 6), respectivamente.

Ferris y Mckenri (1975) y Pinkerton et al. (1999) consideran que en muchos casos la relación densidad poblacional de nematodos/sanidad de las plantas, podría depender de la edad del viñedo, del cultivar y de la presencia de otros factores como el estrés hídrico, suelos pobres, estrés por enfermedades u otras plagas. Seinhorst (1965) informó que la infección por nematodos podría conducir a la reducción de crecimiento, dependiendo de la densidad de nematodos. Pinkerton et al. (1999), consideran que el impacto de los nematodos fitopárásitos en el viñedo se observa cuando la población excede los 1000/250g de suelo. McKenry (1992) por su parte estima que el umbral de daño económico en Vitis vinífera es de $<12$ nematodos en $500 \mathrm{~g}$ de suelo en verano y de $<37$ en invierno. Con respecto a esto, en muestras analizadas en el Laboratorio de Nematodos de la Estación Experimental Agropecuaria Mendoza INTA hemos observado que los viñedos muestran síntomas de ataque, afectando la producción y algunas variables de crecimiento, cuando se exceden los 200 individuos de Meloidogyne spp. por Kg de suelo (datos sin publicar).

De acuerdo con Nicol et al. (1999) los nematodos fitoparásitos siempre se encuentran presentes en los viñedos y si tienen un impacto en el crecimiento, la fisiología de la vid y en última instancia en el rendimiento del cultivo, éste dependerá de las especies de nematodos presentes, sus niveles de población y el genotipo de las raíces de la vid. Por otra parte, estos factores también interactúan de manera compleja con el clima, el tipo y manejo del suelo así como también con los organismos que limitan su población.

Aballay et al. (2009) realizó un estudio en viñedos de Chile infestados con nematodos fitoparásitos y concluye que hay una alta incidencia de los factores ambientales, de suelo y manejo sobre la presencia y distribución de dichos organismos.

\section{CONCLUSIONES}

Hay diferencias significativas entre las dos parcelas estudiadas para los siguientes indicadores vegetativos evaluados: número de J2 de Meloidogyne spp., peso de poda, peso de racimos y área foliar de hojas y feminelas, con un 95\% de confianza. Sin embargo, para ambas comparaciones, la concentración de sólidos solubles, el número de entrenudos y el número de racimos no mostraron diferencias significativas.

Si bien ambas parcelas presentan infestación de juveniles de Meloidogyne spp, la parcela A manifiesta mayor densidad poblacional y mayores daños, por lo que se infiere que los nematodos presentes podrían ser los agentes causales de dicho perjuicio.

Los coeficientes de regresión obtenidos indican que más del 50\% de la variación de tales parámetros se debe a la presencia de nematodos y el porcentaje restante se puede atribuir a otros factores no medidos en este trabajo, excepto para la longitud promedio de brotes.

\section{AGRADECIMIENTOS}

Al Ingeniero Agrónomo Carlos de Borbón por los aportes y las explicaciones. Al Doctor 
Jorge Pérez Peña y a la Ingeniero Agrónomo Graciela Mendoza por las lecturas y correcciones efectuadas.

\section{BIBLIOGRAFÍA}

ABALLAY, E., PERSSON, P. y MARTENSSON, A. 2009. Plant-parasitic nematodes in Chileanvineyards. Nematropica. 39(1):85 - 97.

BROWN,D.J.F., ROBERTSON, W.M. y TRUDGILL, D.L. 1995.Transmission of viruses by plant nematodes. Annual Review Phytopathology. $33: 223$ - 249 .

CARNEIRO, R. M. D. G., ALMEIDA, M. R. A., COFCEWICZ, E. T., MAGUNACELAYA, J. C. y ABALLAY, E. 2007.Meloidogyne ethiopica, a major root-knot nematode parasitizing Vitis vinifera and other crops in Chile. Nematology. 9(5):633 - 642.

CUCCHI, N. y BECERRA, V. 2009. Manual de tratamientos fitosanitarios para cultivos de clima templado bajo riego. Sección III: vid. Primera edición. Ediciones INTA. Mendoza, 865 p.

DI VITO, M., MAGUNACELAYA, J.C., AHUMADA, T. y CATALANO, F. 2009. Relationships between initial population densities of Meloidogyne ethiopica and growth of vinifera grape in pots. Nematology of the Mediterranean. 37:105 - 108.

DOUCET, M. E. 1980. Técnicas básicas de nematología en el suelo. Primera edición. Ediciones INTAIDIA. 34 - 43 p.

DOUCET, M. E. 1991. Nematodos del suelo asociados con vegetales en la República Argentina. Academia Nacional de Agronomía y Veterinaria. Serie de la Academia Nacional de Agronomía y Veterinaria. 24:14.
DOUCET, M. E. 1993. Consideraciones acerca del género Meloidogyne Goeldi, 1887 (Nemata: Tylenchida) y su situación en Argentina. Asociaciones y distribución. Agriscientia. 10:63 - 80.

DOUCET, M. y LAX, P. 2007. El género Meloidogyne y su situación con respecto a la agricultura en la Argentina. Anales de la Academia Nacional de Agronomía y Veterinaria 61:31 - 49

FERRIS, H. y MCKENRY, M.V. 1975. Relationship of grapevine yield and growth to nematodes densities. Journal of Nematology.7:295 - 304.

INSTITUTO NACIONAL DE VITIVINICULTURA (INV). 2012. Registro de viñedos y superficie. En: http://www.inv.gov.ar/PDF/Estadisticas/RegistroVinedos/RegistroVinedosSuperficie2011-2012.pdf, consulta: septiembre, 2014.

JENKINS W.R. 1964. A rapid centrifugal-flotation technique for separating nematodes from soil. Plant Disease Reporter. 48(9):692.

MAGGENTI, A. 1981.General nematology. SpringerSeries in Microbiology. Springer-Verlag. Berlin Heidelberg New York. 372 p.

MAGUNA CELAYA, R.C. y DAGNINO, E. 1999. Nematología Agrícola. Serie Ciencias Agronómicas $\mathrm{N}^{\mathrm{o}}$ 2.Primera edición. Ediciones de la Universidad Nacional de Chile. Santiago de Chile. 282 p.

MCKENRY, M.V. 1992. Nematodes. In: FLAHERTY, D.L., CHRISTENSEN, L.P., LANINI, W.T., MAROIS, J.J., PHILLIPS, P.A. y WILSON, L.T. Grape pest management. Segunda edición. Editado por la Universidad de California, Oakland.400 p.

MELAKEBERHAN, H. y FERRIS, H. 1989. Impact of Meloidogyne incognita on hysiological efficiency of Vitis vinifera. Journal of Nematology. 21(1):74 - 80. 
NICOL, J., STIRLING, B., ROSE, B., MAY P. y VAN HESWIJCK R. 1999. Impact of nematodes on grapevine growth and productivity: current knowledge and future directions, with special reference to Australian viticulture. Australian Journal of Grape and Wine Research. 5:109 - 127.

OLTHOF, TH. H.A. y POTTER, J.W. 1977. Effects of population densites of Meloidogyne haplaon growth and yield of tomato. Journal of Nematology. 9(4):296 - 300.

ORNAT C. y SORRIBAS F. J. 2008. Integrated Management of root-knot Nematodes in Mediterranean Horticultural Crops (pp 295-319) En: CIANCIO, A. y MUKERJI, K.G. Integrated Management and Biocontrol of Vegetable and Grain Crops Nematodes. Primera edición. Springer. 389 p.

PINKERTON, J. N.;FORGE, T.A.;IVORS, K. L. e INGHAM, R.E. 1999. Plant-parasitic nematodes associated with grapevines Vitis vinifera in Oregon vineyards. Supplement to Journal of Nematology.31:624 - 634 .

RODRIGUEZ, M., HERNÁNDEZ, D., ENRIQUE R., GÓMEZ, L., DIAZ-VIRULICHE, L. y PETEIRA, B. 2011. Sintomatología y especies de Meloidogyne asociadas a vid (Vitis vinífera $\mathrm{L}$. cv. Aramond) en Güira de Melena, Artemisa. Revista de Protección Vegetal. 26(2):111 - 117.

SALMERÓN, T. y CABELLO, T. 1989. Incidencia de Meloidogyne incognita en cultivos de tabaco de la Vega de Granada. Boletín de Sanidad Vegetal y Plagas. 4:307 - 314.

SIDDIQI, M.R. 2000.Tylenchida: parasites of plants and insects. Primera edición. Editora $C A B$ International. Gran Bretaña. 833 p.

SEINHORST, J. W. 1965. The relation between nematode density and damage to plants. Nematology.11:137 - 154.

TAYLOR,A. y SASSER,J. 1983. Biología, identificación y control de los nematodos del nódulo de la raíz. Proyecto internacional de Meloidogyne. Artes gráficas de la Universidad de Carolina del Norte. Estados Unidos. 109 p.

VEGA, E. y GALMARINI, H. 1970. Reconocimiento de los nematodes que parasitan los cultivos hortícolas de los departamentos de San Carlos y Tunuyán, Mendoza (Argentina). Ediciones INTA. IDIA. 272:17 - 41.

WILLIAMSOM, V.M. y HUSSEY, R.S. 1996. Nematode pathogenesis and resistence in plants. The Plant Cell. 8:1735 - 1745 